\title{
A Short Intertrial Interval Facilitates Acquisition of Context-Conditioned Fear and a Short Retention Interval Facilitates Its Expression
}

\author{
Gavan P. McNally and R. Frederick Westbrook \\ The University of New South Wales, Sydney, Australia
}

\begin{abstract}
Rats were shocked in a context on two occasions and then tested for fear reactions as indexed by freezing. Rats spent the interval between conditioning trials and between conditioning and test in their home cages. A short interval between context-conditioning trials or between trials involving a discrete conditioned stimulus (CS) produced better learning than longer intervals. A short retention interval between conditioning and test produced better performance than longer intervals. The effects of the intertrial interval on learning are the opposite of those reported previously and are opposite to those predicted by contemporary learning theories. The effects of the training to test interval on performance are predicted by Wagner's sometimes opponent process (SOP) theory (Wagner, 1981).
\end{abstract}

One of the variables that influences the acquisition of a Pavlovian conditioned response is the duration of the interval between successive pairings of the conditioned stimulus (CS) and the unconditioned stimulus (US). When these pairings or trials are separated by long durations, acquisition occurs more rapidly than when they are separated by shorter durations. This relation between acquisition of a conditioned response and the duration of the intertrial interval has been reported in both appetitive and aversive procedures with a range of subjects including pigeons (e.g., Gibbon, Baldock, Locurto, Gold, \& Terrace, 1977), rats (e.g., Barela, 1999), rabbits (Kehoe \& Macrae, 1994), dogs (Pavlov, 1927), and people (Spence \& Norris, 1950). The duration of the intertrial interval also influences the loss or extinction of conditioned responding when CS-US pairings are terminated and the CS is repeatedly presented in the absence of the US. When these CS alone presentations or trials are separated by long durations, extinction occurs more slowly than when they are separated by shorter durations. This relation between extinction and the duration of the intertrial interval has also been documented in both appetitive (e.g., Gibbon, Farrell, Locurto, Duncan, \& Terrace, 1980) and aversive (e.g., Reynolds, 1945) procedures.

These findings could mean that the duration of the interval between trials interacts with the contents of the trial to determine associative formation. Specifically, longer durations may facilitate the CS-US association underlying the production of a conditioned response but impair formation of the inhibitory CS-US association commonly assumed to underlie extinction of that response (see Rescorla, 1979, for discussion). However, studies comparing the conditioned responding of subjects exposed to different intertrial

Gavan P. McNally and R. Frederick Westbrook, School of Psychology, The University of New South Wales, Sydney, Australia.

This research was supported by Grants A00103609 and DP0209523 from the Australian Research Council. We thank Andrew Delamater, Justin Harris, and members of the Australian Learning Group for helpful discussions.

Correspondence concerning this article should be addressed to Gavan P. McNally PhD, School of Psychology, The University of New South Wales, Sydney 2052, Australia. E-mail: g.mcnally@unsw.edu.au intervals confound the interval between training exposures with the interval used to assess this training. Consequently, the differences in conditioned responding that have been observed in both acquisition and extinction could be due to the action of the intertrial interval on the expression of learning rather than the learning itself. For instance, short durations between trials may interfere with the expression of a conditioned response. If so, such durations would impair acquisition but facilitate extinction. One way to determine whether the intertrial interval acts on learning or on its expression is to train subjects with different intertrial intervals but test with common intervals. Any differences on test must reflect differences in what had been learned across training (see Davis, 1970; Davis \& Wagner, 1968, 1969; Lattal, 1999; Rescorla, 1988, for discussion).

The use of this strategy has confirmed that the intertrial interval acts on associative formation rather than (or in addition to) on its expression in performance. For example, Rescorla and Durlach (1987, Experiment 1) arranged for pigeons to receive pairings of CS1-food in Context A and pairings of CS2-food in Context B. The interval separating pairings of CS1-food in Context A was short and that separating CS2-food pairings in Context B was long. Then the birds were tested under extinction in a third context with intermixed short and longer intervals between presentations of each CS. The test revealed greater responding (key pecking) to CS2 than CS1, that is, to the CS trained with the longer interval. Rescorla and Durlach (Experiment 2) also examined the effects of the intertrial interval on extinction. Pigeons received pairings of CS1-food and CS2-food in Contexts A and B. The interval between CS-food trials was equally often short and long. Then CS1 was extinguished in A and CS2 in B. There was a short interval between CS1 presentations in A and a long interval between CS2 presentations in B. Finally, the pigeons were tested in a third context with intermixed short and long intervals between presentations of each CS. The test revealed more loss of the responding (key pecking) to CS1 than to CS2, that is, to the CS that had been extinguished at short intervals (see also Cain, Blouin, \& Barad, 2003).

These findings are those predicted by models that identify associative change with the discrepancy or error between the 
actual US and that predicted. For example, the Rescorla-Wagner (Rescorla \& Wagner, 1972) model holds that all of the stimuli (including contextual stimuli) present on a trial are used to compute predictive error, which, in turn, determines associative change. Thus, the context (B) where CS2-food pairings were separated by a long interval underwent greater loss in associative strength than the context (A) where CS1-food pairings were separated by a short interval. This means that predictive error was greater for the CS reinforced after a long interval (CS2) than the $\mathrm{CS}$ reinforced after a short interval (CS1). Hence, associative formation was greater for CS2 than CS1. These processes also operate in the case of extinction. The context (B) where long intervals separated CS alone presentations would have undergone greater extinction than the context (A) in which the interval between CS alone presentations was short. This differential extinction of the contexts means that there would have been greater predictive error in the case of the short rather than the longer interval because of the larger summed error term. This would have produced more extinction learning to the CS subjected to the short interval (CS1) than to the CS subjected to the long interval (CS2). According to the Rescorla-Wagner model, therefore, the intertrial interval influences acquisition and extinction by acting on context. Longer intervals produce greater extinction of context than short intervals. This extinction of context by long intervals increases predictive error across CS-US pairings, thereby facilitating acquisition, but decreases predictive error across CS alone presentations, thereby impairing extinction.

This explanation applies to the results of studies that confound the interval of time between trials with the time spent in the context between trials but not to the results of studies that break this confound. For instance, Morris, Furlong, and Westbrook (2005, Experiments 1 and 2) shocked rats in a chamber and then exposed them to that chamber in the absence of shock on two occasions. The interval between these extinction trials was spent outside the chamber in the home cage. This interval was either short or long. Finally, rats were tested for their levels of fear (freezing) at common retention intervals-either shortly or some time after the second extinction trial (this interval again spent in the home cage). In contrast to the facilitation of extinction learning reported when the interval between extinction trials was confounded with the time spent in the context, Morris et al. found that a short ( $2 \mathrm{~min}$ ) interval between extinction trials impaired extinction learning: That is, rats subjected to a short intertrial interval froze more when tested some time after the final extinction trial than rats exposed to a long $(24 \mathrm{hr})$ intertrial interval. These investigators additionally reported an effect of the retention interval on the expression of learning. Specifically, rats subjected to the $24 \mathrm{hr}$ interval between the two extinction trials froze more when tested 2 min after the final trial than when tested $24 \mathrm{hr}$ after that trial.

These effects of the training and training-test intervals can be explained by the sometimes opponent process (SOP) model (Wagner, 1978, 1981) and the affective extension of SOP (AESOP; Wagner \& Brandon, 1989). These models identify extinction learning with the formation of inhibitory CS-US associations and assume these are the products of CS nodes in the focus of working memory (an A1 state of activity) concomitantly with those of the US in the periphery (an A2 state of activity). These nodes decay from A1 to A2 and thence to a state of inactivity (I). An additional assumption is that the set of nodes excited to A1 by a CS presentation is the complement of such nodes in A2. Hence, when the interval was such that Trial 2 overlapped with residual A2 activity in the context CS nodes from Trial 1, the context CS presented on Trial 2 was less able to excite its nodes to A1 and therefore less able to enter into the inhibitory association with the US. According to these models, therefore, the impairment of extinction learning by short intertrial intervals was due to a transient reduction in the associability of the context CS. Morris et al. (2005) additionally reported an effect of the retention interval on conditioned responding: Rats exposed to the long interval between extinction trials exhibited more response loss at the longer than the short retention interval. SOP and AESOP explain this relation between the levels of responding and the interval between the final extinction trial and test in terms of the decay time of US nodes from A2. They assume that responding at the long retention interval is entirely determined by the ability of the context to retrieve US nodes to A2. However, they also assume that responding at the short retention interval can receive an additional contribution from US nodes still active in A2 from the recent extinction trial. Thus, SOP and AESOP hold that the decay time of US nodes from A2 determines the function relating conditioned responding to the retention interval.

The present experiments study the effects of the intertrial interval on the acquisition and expression of context-conditioned fear. In the initial experiments, rats were shocked in a context on two occasions and then tested there. The intervals between training exposures as well as between training and test were varied. These intervals were spent in the home cage. Thus, these experiments do not confound the interval between trials with time spent in the context. As noted previously, evidence that longer intervals are more effective in promoting CS-US associations than shorter intervals has come from studies that confound these intervals. It remains to be determined whether such intervals likewise facilitate associative formation when they are spent outside the conditioning context. In fact there are theoretical grounds for expecting short intervals can reduce associative formation. For example, SOP and AESOP hold that a short duration between conditioning trials can produce a transient loss in associability in comparison to longer intervals. This loss in associability occurs when trial $N+1$ overlaps with CS, US, or both nodes still active in A2 from trial $N$. The consequence of such nodes being in A2 is that the CS, US, or both cannot activate nodes to the A1 state of activity that is critical for associative formation. These models make an additional prediction regarding the expression of conditioned responding. Specifically, a short duration between a conditioning trial and a subsequent test presentation of that CS should produce more conditioned responding than a longer duration. This will occur when the test presentation of the CS overlaps with US nodes still active in $\mathrm{A} 2$ from the preceding conditioning trial or with affective arousal from that trial. At a long duration, responding is entirely determined by the ability of the CS to excite US nodes to A2.

\section{Experiment 1}

Experiment 1 studied the influence of the interval between context-conditioning trials on the acquisition and expression of fear reactions in rats. The design of this experiment confounded the interval between training exposures with that between training and test. This was done in order to explore a range of intervals with 
a view to selecting those that maximized between group differences in subsequent experiments. Four groups of rats received two context-conditioning trials and then a test. On each trial, rats were placed in a context and shocked $30 \mathrm{~s}$ later. They were removed from the context $30 \mathrm{~s}$ after shock and returned to their home cages. The test consisted of reexposure to that context in the absence of shock. The intervals between conditioning trials and between the final trial and test were the same within each group but differed across groups. These intervals were $2 \mathrm{~min}, 30 \mathrm{~min}, 3 \mathrm{hr}$, and $24 \mathrm{hr}$.

\section{Method}

Subjects. Thirty-two experimentally naive, male Wistar rats weighing between 300 and $350 \mathrm{~g}$ were used. Rats were obtained from Gore Hill Research Laboratories (St Leonards, NSW, Australia). They were housed in groups of 8 in plastic boxes $(67 \mathrm{~cm}$ length $\times 40 \mathrm{~cm}$ width $\times 22 \mathrm{~cm}$ height) with food and water continuously available. The boxes were kept in an air-conditioned colony room maintained under natural lighting. Each rat was handled for five days prior to the start of the experiment. The experimental procedures followed the ethical guidelines established by the American Psychological Association and were approved by the Animal Care and Ethics Committee of The University of New South Wales.

Apparatus. The four chambers measured $33 \mathrm{~cm}$ in height $\times 31 \mathrm{~cm}$ in length $\times 26 \mathrm{~cm}$ width. The side walls and ceiling were made of aluminum, and the back and front walls were made of clear Perspex. The side walls and ceiling were painted white, and the outside back wall was covered in white cardboard. The floor consisted of stainless steel rods, $5 \mathrm{~mm}$ diameter, spaced $10 \mathrm{~mm}$ apart, center to center, with a tray containing bedding material below. The chambers were located in separate compartments of a wood cabinet. The floor, ceiling, and walls were painted white. The door of each compartment was kept open to permit observation of the rat. Concentrated rose oil (Cara-Mia, Sydney, Australia) was used to provide a distinctive odor. The chambers were cleaned with water, and the oil $(1 \mu \mathrm{l})$ was sprayed over the bedding material between each animal. The room was illuminated by a white fluorescent tube located in the ceiling.

Unscrambled AC 5-Hz shock could be delivered to each floor by a custom-built constant-current generator. The current available to each floor could be adjusted with reference to an in-line milliampere meter. The behavior of each rat while in the chambers was recorded using a camera mounted on the wall facing the open chambers. The camera was connected to a video recorder and monitor located in another room of the laboratory.

Procedure. Rats were weighed and assigned to four weight-matched groups $(n=8)$. During conditioning, rats were placed in the chamber and a $0.35 \mathrm{~mA}, 0.5 \mathrm{~s}$ footshock was delivered $30 \mathrm{~s}$ later. Thirty seconds later the rats were removed from the chambers and returned to their home cages. This episode was followed by a second conditioning episode, identical to the first, either $2 \mathrm{~min}, 3 \mathrm{hr}, 6 \mathrm{hr}$, or $24 \mathrm{hr}$ later, depending on group allocation. Finally, rats were returned to the chambers, either $2 \mathrm{~min}, 3 \mathrm{hr}$, $6 \mathrm{hr}$, or $24 \mathrm{hr}$ later, depending on group allocation, and tested for freezing reactions for $3 \mathrm{~min}$.

Scoring and statistics. In all experiments the test was videotaped, and the levels of freezing were measured every $2 \mathrm{~s}$. Freezing was defined as the absence of all movement other than that required for respiration. The videotape records of each rat were scored by two observers, one of whom was unaware of each rat's group allocation. The interreliability exceeded 0.95 in all experiments. The percentage of observations spent freezing was then analyzed by means of a planned orthogonal contrast testing procedure. The decision-wise error rate $(\alpha)$ was controlled at the 0.05 level for each contrast tested using the procedure described by Harris (1994).

\section{Results}

The mean and standard error of the mean (SEM) levels of freezing displayed on test are shown in Figure 1. Inspection of the

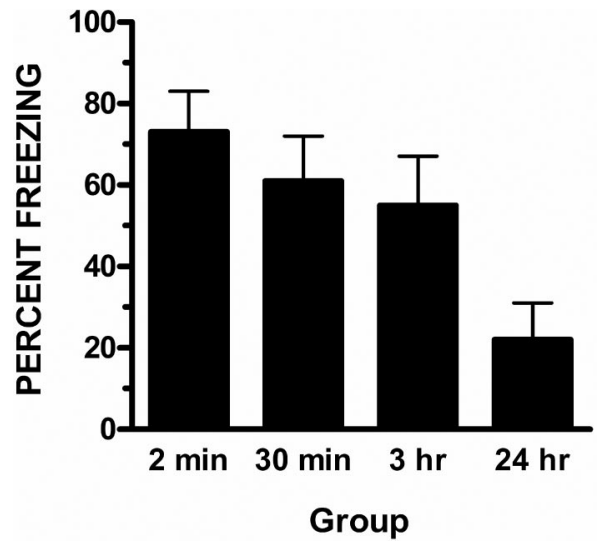

Figure 1. Effect of variations in intertrial interval on contextual fear conditioning. Rats received two shocked exposures to a context separated by $2 \mathrm{~min}, 30 \mathrm{~min}, 3 \mathrm{hr}$, or $24 \mathrm{hr}$ and were tested for fear at the same intervals following last exposure.

figure indicates that levels of freezing varied as a function of the intertrial interval. It is clear from the figure that freezing was inversely related to variations in this interval such that rats trained and tested at the shortest interval $(2 \mathrm{~min})$ displayed the highest levels of freezing and rats trained and tested at the longest interval (24 hr) displayed the lowest levels of freezing. Rats trained and tested at intermediate intervals of $3 \mathrm{hr}$ or $6 \mathrm{hr}$ displayed intermediate levels of freezing. These observations were confirmed by the statistical analysis. There was a significant linear decrease in freezing as the intertrial interval increased from $2 \mathrm{~min}$ to $24 \mathrm{hr}$ $(F(1,28)=11.5 ; p<.05)$

\section{Discussion}

This experiment has produced results opposite of those reported in previous studies. Here, short intertrial intervals resulted in better conditioned responding than longer intervals, whereas in previous studies, longer intertrial intervals resulted in better conditioned responding than short intervals. The design used in this experiment confounded the interval between training exposures with that between training and test. This was done in order to determine those intervals $(2 \mathrm{~min}$ and $24 \mathrm{hr}$ ) that produced the largest differences in performance. Nevertheless, this design means that the results could have been due to the effects of the interval between conditioning trials or to that between the final trial and test. For instance, it is possible that the duration of the interval between conditioning trials modulated associative formation as predicted by SOP and AESOP: That is, the short intervals produced less associative formation on the second trial than longer intervals. However, the duration of the interval between the final conditioning trial and test may also have modulated the expression of this learning in performance: That is, the short intervals produced more responding than longer intervals. In other words, it is possible that the increased performance produced by the short interval between the final trial and test completely obscured the decreased associative formation produced by the short interval between training trials. 


\section{Experiment 2}

One strategy used to determine whether the intertrial interval influences learning or its expression is to train subjects with different durations between conditioning trials and test at common durations. The present experiment used this strategy to determine whether the results obtained in the previous experiment reflected the contrasting effects of the interval between conditioning trials and of the interval between conditioning and test. The design consisted in a $3 \times 3$ factorial. The first factor was the duration of the interval between two context-conditioning trials. These intervals were spent in the home cage and were $2 \mathrm{~min}, 6 \mathrm{hr}$, or $24 \mathrm{hr}$. The second factor was the duration of the interval between the second conditioning trial and test. These intervals were also spent in the home cage and again were $2 \mathrm{~min}, 6 \mathrm{hr}$, or $24 \mathrm{hr}$. The results from the previous study suggest that rats subjected to a short (2 min) interval between the two conditioning trials will freeze more when tested shortly ( $2 \mathrm{~min}$ ) after the second trial than rats exposed to a longer ( $24 \mathrm{hr}$ ) interval between training and tested some time $(24 \mathrm{hr})$ after the second conditioning trial. However, the first question of interest is whether a short interval produces more freezing than longer intervals when rats from each condition are tested at a common long (e.g., $24 \mathrm{hr}$ ) interval. The second is whether a short interval between the second conditioning trial and test produces more freezing than a longer interval.

\section{Method}

Subjects and apparatus. Seventy-two experimentally naive, male Wistar rats weighing between 290 and $350 \mathrm{~g}$ were used. Rats were obtained from the same source and were maintained under the same conditions as in Experiment 1. Rats were handled for five days prior to the start of the experiment. All apparatus was as previously described.

Procedure. Rats were weighed and allocated to nine weight-matched groups $(n=8)$. Each rat was placed in the conditioning chamber and a 0.35 $\mathrm{mA}, 0.5 \mathrm{~s}$ footshock was delivered $30 \mathrm{~s}$ later. Rats were removed from the chambers $30 \mathrm{~s}$ later and returned to their home cages. This shocked exposure was followed $2 \mathrm{~min}, 6 \mathrm{hr}$, or $24 \mathrm{hr}$ later by a second identical shocked exposure. Rats were again removed from the chamber and then tested $2 \mathrm{~min}, 6 \mathrm{hr}$, or $24 \mathrm{hr}$ later. The test was videotaped, and freezing behavior was scored and analyzed as in Experiment 1.

\section{Results}

The mean and SEM levels of freezing displayed on test are shown in Figure 2. Inspection of the figure indicates that levels of freezing varied inversely with the duration of the interval between conditioning trials such that rats exposed to a 2 min interval froze more than rats exposed to longer intervals of $6 \mathrm{hr}$ or $24 \mathrm{hr}$. The figure also suggests that the levels of freezing varied inversely with the duration of the interval between the second conditioning trial and test such that rats tested after a 2 min interval froze more than those tested after $6 \mathrm{hr}$ or $24 \mathrm{hr}$.

The statistical analysis confirmed each of these observations. Averaged across variations in the conditioning-test intervals, freezing was a significant linear function of the interval between the two conditioning trials such that it decreased as this interval increased, $F(1,63)=34.4, p<.05$. Averaged across variations in the interval between conditioning trials, freezing was a significant linear function of the interval between the second trial and test, such that it decreased as this interval increased $(F(1,63)=21.6$;

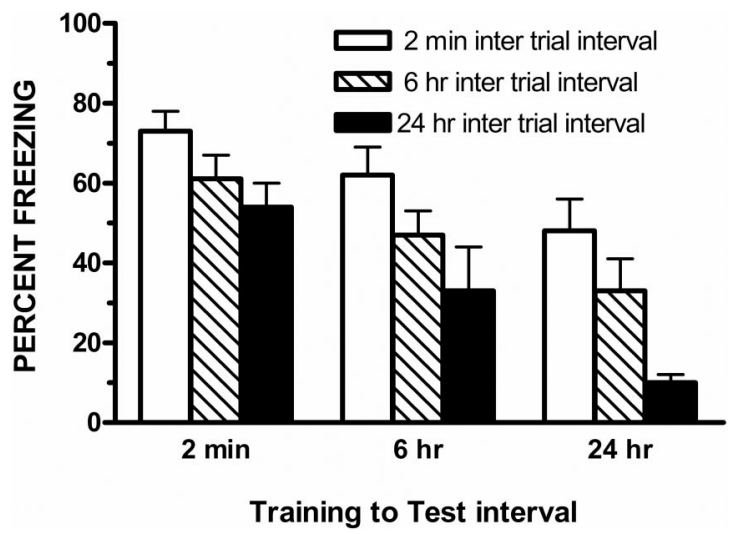

Figure 2. Effects of variations in intertrial and training-to-test intervals on contextual fear conditioning. Rats received two shocked exposures to a context separated by $2 \mathrm{~min}, 6 \mathrm{hr}$, or $24 \mathrm{hr}$ and were tested for fear $2 \mathrm{~min}$, $6 \mathrm{hr}$, or $24 \mathrm{hr}$ following last exposure.

$p<.05)$. Finally the contrast that assessed the interaction between these intervals was not significant $(F(1,63)=1.9 ; p>.05)$.

\section{Discussion}

This experiment has confirmed that rats subjected to short intervals between conditioning trials and between the final conditioning trial and test (Group $2 \mathrm{~min}: 2 \mathrm{~min}$ ) freeze more than rats exposed to longer intervals (e.g., Group $24 \mathrm{hr}$ : $24 \mathrm{hr}$ ). It has also provided evidence that the interval between the conditioning trials as well as that between conditioning and test contribute to these differences. Specifically, rats exposed to a short interval between the conditioning trials froze more than rats exposed to longer intervals when tested at common intervals. Thus, this difference between the test levels of freezing must have been due to what had been learned previously. That is, short intervals produced better learning than did longer intervals. There was also an effect of the interval between the final conditioning trial and test: Rats subjected to short intervals froze more than rats exposed to longer intervals. Thus, a recent shocked exposure to context produced more freezing than a remote exposure.

\section{Experiment 3}

These results are the opposite of those reported previously in both appetitive and aversive procedures. As noted in the introduction, subjects trained and tested with different intertrial intervals typically exhibit better conditioned performance when the durations of these intervals are long than when they are short. This relation between the intertrial interval and the development of conditioned performance has been observed in both appetitive and aversive procedures. Further, the available evidence is that differences in associative formation contribute to these differences in the development of conditioned performance. Using an appetitive procedure with pigeons, Rescorla and Durlach (1987) reported that longer intervals produced better conditioned performance than short intervals when the birds were tested at common intervals. In contrast, the results of the previous experiment showed that rats trained and tested with short intertrial intervals (e.g., Group 2 min: 
$2 \mathrm{~min}$ ) froze more than rats trained and tested with longer intervals (e.g., Group 24 hr: 24 hr). Further, they also revealed that differences in associative formation contributed to these differences in the test levels of freezing. Rats trained with short intervals froze more than rats trained with longer intervals when tested at common intervals.

One of the many differences that may underlie these contrasting results is the present use of a chamber or context as the CS. Previous studies of the role played by the intertrial interval in the development of conditioned performance have used a discrete CS. A second difference, of course, is where the subjects spend the intertrial interval. In the present experiments, rats spent this interval in their home cages, whereas in previous studies subjects spent the intertrial interval in the context where the CS-US pairings occur. This experiment used a discrete CS to determine the generality of the results observed in Experiment 2. The design was a $2 \times 2$ factorial where the first factor was the duration of the interval ( $2 \mathrm{~min}$ or $24 \mathrm{hr}$ ) between the two conditioning trials and the second was the interval ( $2 \mathrm{~min}$ or $24 \mathrm{hr}$ ) between the second trial and test. Thus, this experiment uses a discrete CS but differs from previous studies in terms of where the subjects spend the intertrial intervals. In this experiment, the rats spent this interval in their home cages.

\section{Method}

Subjects and apparatus. Thirty-two experimentally naive, male Wistar rats weighing between 290 and $360 \mathrm{~g}$ were used. Rats were obtained from the same source and were maintained under the same conditions as described in Experiment 1. Rats were handled for five days prior to the start of the experiment.

Conditioning and CS testing were conducted in different chambers. The chambers previously described were used for conditioning. The US was a $0.5 \mathrm{~s}, 0.35 \mathrm{~mA}$ unscrambled $\mathrm{AC} 50-\mathrm{Hz}$ shock from a constant-current generator that was delivered to the floor of each chamber. The current available to each floor could be adjusted using an in-line milliampere meter. A second set of two plastic chambers $(16 \mathrm{~cm}$ height $\times 40 \mathrm{~cm}$ length $\times 26 \mathrm{~cm}$ width) was used to test performance to the auditory CS. The front of each of these chambers was constructed of Perspex. The floor, side, and rear walls were made of plastic, and the roof of stainless steel rods. These chambers were located on the roof of the wooden cabinet that contained the conditioning chambers. In both sets of chambers, the discrete auditory CS consisted of a $10 \mathrm{~s} 74 \mathrm{~dB}$ clicker $(10-\mathrm{Hz}$ spike; rise time $<10$ $\mu \mathrm{s}$, decay time $250 \mu \mathrm{s}$ ) delivered from a speaker located in the ceiling of the experimental room. The background noise in the room was $69 \mathrm{~dB}$. The stimulus and background intensities were measured with a sound level meter (A scale; Type 2235, Brüel-Kjaer Instruments, Marlborough, MA) whose microphone was placed in the center of each chamber.

Procedure. Rats were weighed and allocated to four weight-matched groups $(n=8)$. Each rat was placed in the conditioning chamber and the $10 \mathrm{~s}$ CS was presented $20 \mathrm{~s}$ later. The CS coterminated with the $0.35 \mathrm{~mA}$, $0.5 \mathrm{~s}$ footshock. Rats were removed from the chambers $30 \mathrm{~s}$ later and returned to their home cages. This shocked exposure was followed $2 \mathrm{~min}$ or $24 \mathrm{hr}$ later by an identical shocked exposure. After this second shocked exposure rats were again removed from the chamber and then tested either $2 \mathrm{~min}$ or $24 \mathrm{hr}$ later. On test, rats were placed in the test chambers and context-elicited freezing was scored for 2 min prior to presentation of the CS for $5 \mathrm{~min}$. The test was videotaped, and freezing behavior was scored and analyzed as described in Experiment 1.

\section{Results}

The mean and SEM levels of freezing by rats in each of the groups on test are shown in Figure 3. The left side of the figure shows freezing in the neutral context prior to CS onset, and the right shows freezing to the CS. Inspection of the left graph indicates that there was little freezing in the test context by rats in any of the groups. In contrast, presentation of the CS provoked substantial freezing. Inspection of the right graph suggests that the levels of freezing varied inversely with the duration of the interval between conditioning trials such that rats exposed to a $2 \mathrm{~min}$ interval between the two conditioning trials froze more than rats exposed to intertrial intervals of $24 \mathrm{hr}$. Further, the levels of freezing also appear to have varied inversely with the duration of the interval between the second conditioning trial and test such that rats tested after a $2 \mathrm{~min}$ interval froze more than those tested after $24 \mathrm{hr}$.

The statistical analysis of CS freezing confirmed each of these observations. There were no differences between groups in freezing in the neutral context prior to CS onset (all F's $(1,28)<1.04$; $p>.05)$. Overall, there was significantly more freezing during the CS presentation than during exposure to the neutral context prior to $\mathrm{CS}$ presentation $(F(1,28)=24.7 ; p<.05)$. There was a significant main effect of intertrial interval $(F(1,28)=8.0 ; p<$ $.05)$, so that rats conditioned with a 2 min intertrial interval showed significantly more freezing than rats conditioned with a $24 \mathrm{hr}$ interval. There was a significant main effect of the training to test interval $(F(1,28)=9.2 ; p<.05)$, so that rats tested after a 2 min intertrial interval showed significantly more freezing than rats tested after a $24 \mathrm{hr}$ interval. Finally there was no interaction between these two intervals $(F(1,28)=1.4, p>.05)$.

\section{Discussion}

This experiment has shown that fear of a discrete CS is subject to the same influences of variations in intertrial and training to test intervals as fear to a context. Rats were placed in a context and exposed to a CS-shock pairing on two occasions and then tested for fear of the CS in a neutral context. A short $(2 \mathrm{~min})$ interval

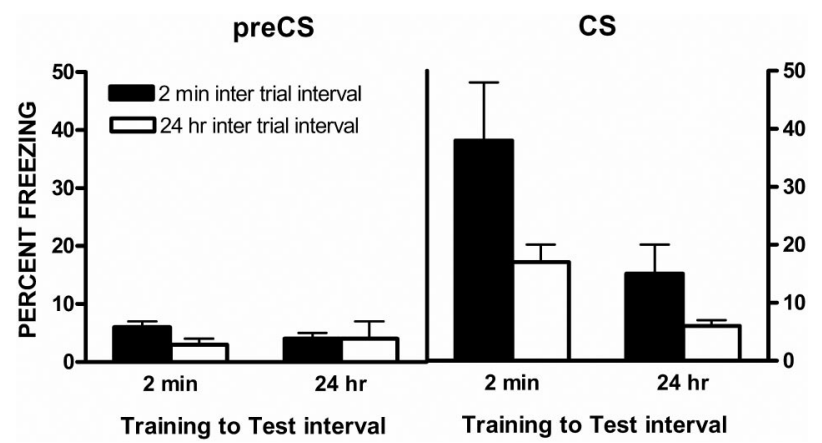

Figure 3. Effects of variations in intertrial and training-to-test intervals on discrete conditioned stimulus (CS) fear conditioning. Rats received two shocked exposures to a CS separated by $2 \mathrm{~min}$ or $24 \mathrm{hr}$ and were tested for fear to that CS in a novel context $2 \mathrm{~min}$ or $24 \mathrm{hr}$ following last exposure. The left side shows levels of freezing to the novel context prior to CS presentation. The right side shows levels of freezing during CS presentation 
between the two conditioning trials produced more learning about the CS than a longer $(24 \mathrm{hr})$ interval, and a short interval between the final CS conditioning trial and test produced more fear than a longer interval. Further, the effect of each of these intervals was independent of the other. The effect of the interval between the final conditioning trial and test was not an artifact of any freezing provoked by the recent US. Rats tested shortly after that conditioning trial exhibited just as little freezing on exposure to the neutral test context as did rats tested some time after the conditioning trial. Nevertheless, such rats differed in their levels of freezing when tested with the CS. Thus, the freezing observed on test in Experiments 1 and 2 was not an unconditioned response elicited by a recent shock; it was a conditioned response elicited by a context that had previously been paired with shock.

\section{Experiment 4}

The results of the previous experiments are partially consistent with those predicted by SOP. On the one hand, the effects of the interval between the final conditioning trial and test are consistent with the hypothesis that test performance reflects summation of self- and associatively generated priming of US nodes in an A2 state of activity at short but not longer intervals. Specifically, SOP and AESOP assume that freezing is the response to US nodes in an A2 state of activity, and that these nodes are activated to that state by the retrieval action of an associated CS or by a recent US presentation. Thus, short intervals produced greater levels of freezing than longer ones because the freezing produced by the US nodes in A2 from the recent conditioning trial summated with the nodes activated to that state by the associated context CS. On the other hand, the effects of the interval between conditioning trials on learning are inconsistent with the hypothesis that longer intervals are more effective than short intervals because of the loss in associability that can be produced by the latter. This loss occurs when the duration of the interval between trials is such that trial $N+1$ coincides with CS and/or US nodes still in A2 from trial $N$.

The procedure used in Experiments 2 and 3 controlled the duration of each conditioning trial while varying the time (spent in the home cages) between these trials. However, each conditioning trial necessarily entailed the rats being removed from their home cages and subjected to a period of social isolation across the conditioning trial. Therefore, that procedure confounded the interval between the two conditioning trials with the interval between two bouts of social isolation. It is possible that the recent stress produced by handling, removal from the home cages, and social isolation mediated the differences in learning among rats subjected to the short or longer interval between conditioning trials. There was a second confound in the previous designs. The interval between the two conditioning trials was confounded with the interval between two US presentations. That is, subjects were not just exposed to a short or long interval between the two contextconditioning trials (e.g., Experiment 2), they were also exposed to a short or long interval between the two shocks. Therefore, it is possible that the critical interval for the subsequent differences in the levels of freezing was the interval between the two shocks rather that the interval between the two context-shock exposures.

The present experiment varied the interval between conditioning trials while controlling for any stress produced by handling, removal from the home cage, and social isolation. In addition, it controlled for the differences in the interval between shocks. The procedure consisted of shocking rats in the target context (A) on two occasions separated by either a short $(2 \mathrm{~min})$ or long $(24 \mathrm{hr})$ interval. In addition, rats were shocked in a second context (B). For rats in Group $\mathrm{A}+\mathrm{B}+\mathrm{A}+$, the interval between the two shocked exposures to A was long ( $24 \mathrm{hr}$ ) while the interval between the exposure to B and to A was short (2 min); for those in Group $\mathrm{B}+/ \mathrm{A}+\mathrm{A}+$, the interval between the two exposures to $\mathrm{A}$ was short $(2 \mathrm{~min}$ ) while the interval between the exposure to $\mathrm{B}$ and to A was long ( $24 \mathrm{hr}$ ). Finally, rats in each of these conditions were tested in A either $2 \mathrm{~min}, 24 \mathrm{hr}$, or $48 \mathrm{hr}$ after the final shocked exposure to A.

\section{Methods}

Subjects and apparatus. Forty-eight experimentally naive, male Wistar rats weighing between 300 and $350 \mathrm{~g}$ were the subjects. Rats were obtained from the same source and were maintained under the same conditions as in Experiment 1. Rats were handled for five days prior to the start of the experiment. Two sets of chambers served as Context A and Context B in a counterbalanced fashion. The first set was identical to those described previously. The second set measured $33 \mathrm{~cm}$ in height $x 31 \mathrm{~cm}$ in length $x$ $26 \mathrm{~cm}$ in width. The side walls and ceiling were made of aluminum, and the back and front walls were made of clear Perspex. The side walls and ceiling were painted black, and the outside back wall was covered in black cardboard. The floor consisted of stainless steel rods, $5 \mathrm{~mm}$ diameter, spaced $10 \mathrm{~mm}$ apart, center to center, with a tray containing bedding material below. The chambers were located in separate compartments of a wooden cabinet. The floor, ceiling, and walls were painted white. The door of each compartment was kept open to permit observation of the rat. A concentrated banana essence (Rockman, Sydney, Australia) was used to provide a distinctive odor in the context. The chambers were cleaned with water, and the essence $(1 \mu l)$ was sprayed over the bedding material between each animal. Pilot data had indicated little generalization of freezing between these two sets of chambers. The room was illuminated by a red fluorescent tube located in the ceiling. All other apparatus was as previously described.

Procedure. Rats were weighed and allocated to five weight-matched groups $(n=8)$. On Day 1 , each rat was placed in a conditioning chamber and a $0.35 \mathrm{~mA}, 0.5 \mathrm{~s}$ footshock was delivered $30 \mathrm{~s}$ later. Rats were removed from the chambers after $30 \mathrm{~s}$ and returned to their home cages. The chamber was $\mathrm{A}$ for rats in Group $\mathrm{A}+\mathrm{B}+\mathrm{A}+$, and $\mathrm{B}$ for rats in Group $\mathrm{B}+/ \mathrm{A}+\mathrm{A}+$. Twenty-four hours later rats were again placed in the conditioning chamber, and a $0.35 \mathrm{~mA}, 0.5 \mathrm{~s}$ footshock was delivered after $30 \mathrm{~s}$. Rats were removed from the chambers $30 \mathrm{~s}$ after shock and returned to their home cages. This chamber was $\mathrm{B}$ for rats in Group $\mathrm{A}+\mathrm{B}+\mathrm{A}+$, and $\mathrm{A}$ for those in Group $\mathrm{B}+/ \mathrm{A}+\mathrm{A}+$. This shocked exposure was followed at $2 \mathrm{~min}$ by another identical shocked exposure in A. Rats were returned to Chamber A after $2 \mathrm{~min}, 24 \mathrm{hr}$, or $48 \mathrm{hr}$ after this last shocked exposure according to group allocations, and their freezing behavior was recorded for $5 \mathrm{~min}$.

\section{Results}

The mean and SEM levels of freezing displayed on test are shown in the left side of Figure 4. Inspection of the figure suggests that short intervals between the two conditioning trials with $\mathrm{A}$ (Group $\mathrm{B}+/ \mathrm{A}+\mathrm{A}+$ ) produced better learning than longer intervals (Group $\mathrm{A}+/ \mathrm{B}+\mathrm{A}+$ ) when assessed at common intervals of $24 \mathrm{hr}$ and $48 \mathrm{hr}$ but not at a 2 min interval. That is, rats in Group $\mathrm{B}+/ \mathrm{A}+\mathrm{A}+$ froze more when tested $24 \mathrm{hr}$ or $48 \mathrm{hr}$ after the final conditioning trial than rats in Group $\mathrm{A}+/ \mathrm{B}+\mathrm{A}+$. However, there 


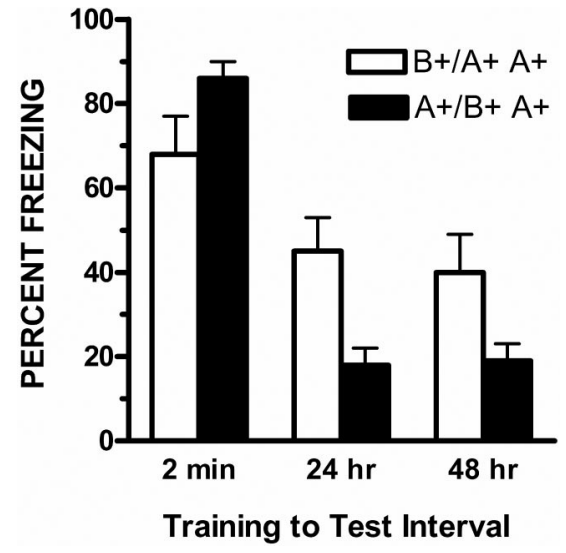

Figure 4. Role of social isolation and recent exposure to the shock in determining the effects of intertrial and training-to-test intervals on contextual fear conditioning. Rats received two shocked exposures to the target context A separated by either 2 min (Group B +/A + A+) or $24 \mathrm{hr}$ (Group $\mathrm{A}+\mathrm{B}+\mathrm{A}+$ ) and also received a shocked exposure to context $\mathrm{B} 2 \mathrm{~min}$ (Group A+/B $+\mathrm{A}+$ ) or $24 \mathrm{hr}($ Group B+/A $+\mathrm{A}+$ ) prior to the second exposure to A. Rats were tested for fear to context A $2 \mathrm{~min}, 24 \mathrm{hr}$, or 48 $\mathrm{hr}$ after the last shocked exposure.

were no such differences when rats from each of these groups were tested at a common interval of $2 \mathrm{~min}$. The figure also suggests that shorter intervals between the final conditioning trial and test also determined the levels of freezing: Rats tested shortly after the final conditioning trial froze more than rats tested some time after that trial.

The statistical analysis confirmed these observations. There was no significant main effect of the interval between the two shocked exposures to the target A context, as overall there were no significant differences between the test levels of freezing by rats exposed to the short interval between A trials (Group B+/A $+\mathrm{A}+$ ) or a longer interval between these trials (Group $\mathrm{A}+\mathrm{B}+\mathrm{A}+$ ) $(F(1,42)=1.7 ; p>.05)$. There was a significant main effect of the interval between the final conditioning trial and test such that, overall, rats tested after a short (2 min) interval froze significantly more than rats tested at longer $(24 \mathrm{hr}$ and $48 \mathrm{hr})$ intervals $(F(1$, $42)=34.6 ; p<.05)$. There was no overall difference in freezing between rats tested $24 \mathrm{hr}$ or $48 \mathrm{hr}$ after the final conditioning trial $(F(1,42)<1 ; p>.05)$. Notably, there was a significant interaction such that the differences between rats trained with the 2 min interval between the A trials (Group $\mathrm{B}+/ \mathrm{A}+\mathrm{A}+$ ) versus those trained with the longer interval between these trials (Group $\mathrm{A}+$ / $\mathrm{B}+\mathrm{A}+$ ) were greater when rats from each condition were tested at $24 \mathrm{hr}$ and $48 \mathrm{hr}$ than when tested at $2 \min (F(1,42)=10.1 ; p<$ $.05)$. There was no interaction between the contrast assessing the difference between the 24 versus $48 \mathrm{hr}$ conditioning to test interval and the contrast assessing the difference between Groups $\mathrm{A}+\mathrm{B}+$ $\mathrm{A}+$ and $\mathrm{B}+/ \mathrm{A}+\mathrm{A}+(F(1,42)<1 ; p>.05)$. Post hoc tests confirmed that rats subjected to the short interval between conditioning trials (Group $\mathrm{B}+/ \mathrm{A}+\mathrm{A}+$ ) froze significantly more than those exposed to a longer interval (Group $\mathrm{A}+\mathrm{B}+\mathrm{A}+$ ) when rats from each of these conditions were tested at common intervals of 24 and $48 \mathrm{hr}(F(1,42)=11.89 ; p<.05)$ but that there were no differences between groups at the common 2 min interval $(F(1$, 42) $=3.5 ; p>.05)$.

\section{Discussion}

This experiment has confirmed that a short interval between the final context-conditioning trial and test produces more freezing than longer intervals. Independent of the interval between the conditioning trials, rats tested shortly after the final conditioning trial froze more than rats tested some time after that trial. This experiment has also shown that a short interval between two shocked exposures does not necessarily produce better learning than longer intervals. Rather, the significant interaction between intertrial and training to test intervals in this experiment shows that short intervals between two shocked exposures to the same context (with a remote shocked exposure to a different context) produce better learning than longer intervals between those shocked exposures (with a recent shocked exposure to a different context) when assessed some time after conditioning but not when assessed shortly after conditioning. Rats exposed to the 2 min interval between the shocked exposures to the target context (Group B + / $\mathrm{A}+\mathrm{A}+$ ) froze more than rats exposed to a longer interval (Group $\mathrm{A}+/ \mathrm{B}+\mathrm{A}+)$ when rats from each condition were tested at common intervals of 24 or $48 \mathrm{hr}$. Thus, this experiment suggests that the critical interval for learning is that between the shocked exposures to context $\mathrm{A}$ rather than that between shocks, whereas this latter interval is critical for the facilitatory effect on performance.

\section{General Discussion}

This series of experiments has shown that a short interval between aversive conditioning trials produces more fear than longer intervals. In Experiment 1, rats that received a short (e.g., 2 min) interval between shocked exposures to a context exhibited more fear (freezing) than rats exposed to longer (e.g., $24 \mathrm{hr}$ ) intervals. These rats differed not only in the interval ( 2 min or 24 hr) between the context-conditioning trials but also in the interval between the final trial and test. Hence, the differences between the test levels of freezing could have been due to the effects of the interval on learning or on its expression in performance. The strategy used to determine whether the duration of the interval acted on learning or on its expression in performance was to subject rats to different intervals between the conditioning trials but test after common intervals. Experiment 2 showed that a short interval between context-conditioning trials produced more freezing at test than longer intervals. Since the rats were tested at common intervals, the differences between their levels of freezing must have been due to differences in what had been learned previously. Experiment 3 found similar results when a discrete CS was paired with shock. Rats exposed to a short interval between CS-shock pairings froze more than rats exposed to longer intervals when rats from each condition were tested at common intervals These experiments also revealed an effect of the interval between conditioning and test. Regardless of the interval between the context-conditioning trials, a short interval between the final conditioning trial and test produced more freezing than longer intervals. Likewise, in Experiment 3, a short interval between the final CS-shock pairing and test produced more freezing than a longer interval.

These results were produced in designs that confounded the interval between the shocked exposures to the context or CS with 
the interval between shocks. Hence, it is possible that it is simply the recent occurrence of shock that increases learning on a subsequent conditioning trial. However, the design used in Experiment 4 controlled for the interval between shocks while varying the interval between conditioning trials to the target context (A). That experiment subjected rats to either a short $(2 \mathrm{~min})$ or long $(24 \mathrm{hr}$ ) interval between shocked exposures to context A while additionally arranging a shocked exposure to context $\mathrm{B}$. Rats receiving a short interval between the shocked exposures to $\mathrm{A}$ had been shocked in B $24 \mathrm{hr}$ earlier (Group B+/A $+\mathrm{A}+$ ), while those receiving the long interval between the shocked exposures to $\mathrm{A}$ were shocked in $\mathrm{B}$ shortly before the second shocked exposure to $\mathrm{A}$ (Group $\mathrm{A}+\mathrm{B}+\mathrm{A}+$ ). The results of this experiment confirmed that the critical interval for learning was that between the shocked exposures to context A rather than the interval between shock and the subsequent shocked exposure to that context. Specifically, rats exposed to the short interval between the context A conditioning trials (Group $\mathrm{B}+/ \mathrm{A}+\mathrm{A}+$ ) froze more than rats exposed to the longer interval between these trials (Group $A+/ B+A+$ ) when rats from each condition were tested at common intervals of $24 \mathrm{hr}$ and $48 \mathrm{hr}$.

The facilitation of learning by a short intertrial interval is the opposite of that reported previously (e.g., Rescorla \& Durlach, 1987, Experiment 1). A major difference between the present procedure and those used previously is where subjects spent this interval: In the present experiments, this interval was spent outside the conditioning context (in the home cages), whereas in previous studies, it was spent in the conditioning context. This difference is important because of the role accorded the context or background in regulating the effect of the interval on associative formation. Many contemporary models (e.g., Rescorla \& Wagner, 1972; Wagner, 1981; Wagner \& Brandon, 1989) assume that all the cues present on a trial (including contextual cues) are used to compute predictive error and, hence, associative change. Such models thus predict that longer intervals will produce better learning about the CS than short intervals because of differences in the predictive value of contextual cues. These differences occur because longer intervals extinguish contextual or background cues and this extinction increases predictive error and, hence, associative formation to the CS. In the absence of variations in predictive error produced by extinction of context, such models offer no predictions as to the effects of the intertrial interval on learning.

Models that address the role of the intertrial by appealing to the dynamics of working memory rather than, or in addition to, variations in predictive error (e.g., Wagner, 1978) predict, if anything, that short intervals impair rather than facilitate associative learning. This prediction comes from the proposals that CS and US representations that are still in an A2 state from the preceding trial reduce the ability of the subsequent trial to excite the corresponding representations to an A1 state of activity. As the formation of CS-US associations is the product of their representations in an A1 state of activity, a recently preceding trial produces a loss of associability. Finally, the present results are also relevant to models that identify the development of a conditioned response with the ratio of the intertrial interval and the trial duration (e.g., Gallistel \& Gibbon, 2000; Gibbon \& Balsam, 1981). Such models note that studies comparing the responding of subjects exposed to short versus long intertrial intervals typically also expose their subjects to equal trial durations. Thus, long intervals produce better conditioned responding because the ratio of the intertrial interval (I) to trial duration (T) is greater than the I:T ratio at the short interval. Further, when these ratios are equated, conditioned responding develops at equivalent rates across a wide range of absolute I and $\mathrm{T}$ values. These models predict equivalent conditioned responding when the intertrial interval was spent outside the conditioning context because the trial durations are equivalent and subjects do not time the interval spent outside the target context or do not use this information to compute the I:T ratio. Alternatively, such models predict that long intervals produce better conditioned responding than short ones because subjects do time such intervals and the I:T ratio at the longer intertrial interval was vastly greater than at the shorter interval (intertrial intervals of $24 \mathrm{hr}$ vs. $2 \mathrm{~min}$ and an equivalent trial duration of $60 \mathrm{~s}$ ).

The better learning produced by a short interval could be viewed in terms of a transient increase in the effectiveness of the CS or US. However, the critical interval was that between the conditioning trials rather than that between US exposures. Hence, it seems that the initial conditioning trial produced better learning by increasing the effectiveness of the CS rather than of the US. There are, of course, grounds for supposing that a conditioning trial does serve to increase the effectiveness of the CS. For example, Mackintosh (1975) has proposed that attention to a CS is increased if it is a better predictor of the US than the other available cues, and decreased if it is a worse predictor. This model explains the results obtained by studies that confound the interval between conditioning trials with the time spent in the context between these trials. It does so by supposing that longer intervals extinguish the context and thereby increase attention to the CS that is a better predictor of the US. To explain the present results, this model needs to assume that the initial conditioning trial resulted in the subsequent allocation of attention to the CS that declined across time. In other words, a recent conditioning trial results in attention to a predictive CS and the level of this attention is regulated by the time since the conditioning trial.

The present series of experiments also demonstrated that given equal associative strength, the ability of a CS to elicit conditioned performance was inversely related to the interval between training and test. This facilitation of performance by a short interval between conditioning and test is consistent with the hypothesis that attention to the CS is greater at such intervals. Other things being equal, that is, associative strength, the ability of a CS to provoke conditioned performance will be regulated by the effectiveness with which it is processed (e.g., Schmajuk, Gray, \& Lam, 1996). Alternatively, this facilitation of performance can be viewed in terms of models such as SOP and AESOP. These identify conditioned responding with those responses elicited by a US in an A2 state of activity and thus suppose that such responding is elicited either by the associative action of an antecedent CS or by a US whose nodes have decayed from A1 into an A2 state of activity. Thus, the level of responding at long intervals between conditioning and test is determined entirely by the strength of the CS-US association, that is, by the ability of the CS to excite the US representation to A2. However, the level of responding at a shorter interval can receive an additional contribution from US representations still in A2 from the preceding conditioning trial. Hence, responding at short intervals is greater than at longer intervals because of the greater proportion of US nodes in A2 at test. Essentially, such models propose that the function relating re- 
sponding to the interval between conditioning and test reflects the time taken for US nodes to decay from A2 to inactivity.

Finally, the present results are similar to those reported in the case of extinction (Morris et al., 2005). A short interval between conditioning trials or between extinction trials produced more freezing than longer intervals when subjects in each set of experiments were tested at common retention intervals. Likewise, a short interval between the final conditioning trial or the final extinction trial and test produced more freezing than longer intervals. Taken together, these findings show that a short interval between conditioning trials facilitates acquisition of fear reactions while a short interval between extinction trials impairs their loss. They also show that a short interval between a conditioning or an extinction trial and test produces more freezing than longer intervals. Thus, short intervals produce better fear learning and better expression of this learning in performance.

\section{References}

Barela, P. B. (1999). Theoretical mechanisms underlying the trial-spacing effect in Pavlovian fear conditioning. Journal of Experimental Psychology: Animal Behavior Processes, 25, 177-193.

Cain, C. K., Blouin, A. M., \& Barad, M. (2003). Temporally massed CS presentations generate more fear extinction than spaced presentations. Journal of Experimental Psychology: Animal Behavior Processes, 29, 323-333.

Davis, M. (1970). Effects of interstimulus interval length and variability on startle-response habituation in the rat. Journal of Comparative and Physiological Psychology, 72, 177-192.

Davis, M., \& Wagner, A. R. (1968). Startle responsiveness after habituation to different intensities of tone. Psychonomic Science, 12, 337-338.

Davis, M., \& Wagner, A. R. (1969). Habituation of startle response under incremental sequence of stimulus intensities. Journal of Comparative \& Physiological Psychology, 67, 486-492.

Gallistel, C. R., \& Gibbon, J. (2000). Time, rate and conditioning. Psychological Review, 107, 289-344.

Gibbon, J., Baldock, M. D., Locurto, C., Gold, L., \& Terrace, H. S. (1977). Trial and intertrial durations in autoshaping. Journal of Experimental Psychology: Animal Behavior Processes, 3, 264-284.

Gibbon, J., \& Balsam, P. (1981). Spreading association in time. In C. M. Locurto, H. S. Terrace, \& J. Gibbon (Eds.), Autoshaping and conditioning theory (pp. 219-253). New York: Academic Press.

Gibbon, J., Farrell, L., Locurto, C. M., Duncan, H. J., \& Terrace, H. S. (1980). Partial reinforcement in autoshaping with pigeons. Animal Learning \& Behavior, 8, 45-59.

Harris, R. J. (1994). ANOVA: An Analysis of Variance primer. Itasca, IL: FE Peacock.

Kehoe, E. J., \& Macrae, M. (1994). Classical conditioning of the rabbit nictitating membrane response can be fast or slow: Implications for Lennartz and Weinberger's (1992) two-factor theory. Psychobiology, 22, $1-4$.
Lattal, K. M. (1999). Trial and intertrial durations in Pavlovian conditioning: Issues of learning and performance. Journal of Experimental Psychology: Animal Behavior Processes, 25, 433-450.

Mackintosh, N. J. (1975). A theory of attention: Variations in the associability of stimulus with reinforcement. Psychological Review, 82, 276298.

Morris, R. W., Furlong, T. M., \& Westbrook, R. F. (2005). Recent exposure to a dangerous context impairs extinction and reinstates lost fear reactions. Journal of Experimental Psychology: Animal Behavior Processes, 31, 40-55.

Pavlov, I. P. (1927). Conditioned reflexes (G. V. Anrep, Trans.). New York: Dover.

Rescorla, R. A. (1979). Conditioned inhibition and extinction. In A. Dickinson \& R. A. Boakes (Eds.), Mechanisms of learning and motivation: A tribute volume to Jerzy Konorski (pp. 83-110). Hillsdale, NJ: Erlbaum.

Rescorla, R. A. (1988). Behavioral studies of Pavlovian conditioning. Annual Review of Neuroscience, 11, 329-352.

Rescorla, R. A., \& Durlach, P. J. (1987). The role of context in intertrial interval effects in autoshaping. Quarterly Journal of Experimental Psychology: Comparative and Physiological Psychology, 39(B), 35-48.

Rescorla, R. A., \& Wagner, A. R. (1972). A theory of Pavlovian conditioning: Variations in the effectiveness of reinforcement and nonreinforcement. In A. H. Black \& W. F. Prokasy (Eds.), Classical conditioning II: Current research and theory (pp. 64-99). New York: Appleton-Century-Crofts.

Reynolds, B. (1945). Extinction of trace conditioned responses as a function of the spacing of trials during the acquisition and extinction series. Journal of Experimental Psychology, 35, 81-95.

Schmajuk, N. A., Gray, J. A., \& Lam, Y. W. (1996). Latent inhibition: A neural network approach. Journal of Experimental Psychology: Animal Behavior Processes, 22, 321-349.

Spence, K. W., \& Norris, E. B. (1950). Eyelid conditioning as a function of the intertrial interval. Journal of Experimental Psychology, 40, 716720 .

Wagner, A. R. (1978). Expectancies and the priming of STM. In S. H. Hulse, H. Fowler, \& W. K. Honig (Eds.), Cognitive processes in animal behavior (pp. 177-209). Hillsdale, NJ: Erlbaum.

Wagner, A. R. (1981). SOP: A model of automatic memory processing in animal behavior. In N. E. Spear \& R. R. Miller (Eds.), Information processing in animals: Memory mechanisms (pp. 5-47). Hillsdale, NJ: Erlbaum.

Wagner, A. R., \& Brandon, S. E. (1989). Evolution of a structured connectionist model of Pavlovian conditioning (AESOP). In S. B. Klein \& R. R. Mowrer (Eds.), Contemporary learning theories: Pavlovian conditioning and the status of traditional learning theory (pp. 149-189). Hillsdale, N. J: Erlbaum.

Received August 2, 2005

Revision received January 3, 2006

Accepted January 3, 2006 